\title{
Community and heritage management: Linking stakeholders to archaeological sites in Kichakbadh
}

\author{
Abhijeet Thapa
}

\begin{abstract}
Community has been much of a striking terminology these days when associated with heritage management. Communities living nearby heritage sites, while at one hand are agents of conservation, on the other hand are sources of destruction in heritage sites and agents of risks. As such, this research unfolds the contested roles of local people for taking ownership of heritage management, understanding heritages, transmitting oral intangible values and valuing destination image at Kichakbadh Province -1, Nepal. The research, aimed at studying heritage management issues around the site has been supplemented by multiple field visits, numerous questionnaires and interviews with locals, visitors and experts. This article chiefly deals with the second phase of author's exploration carried out on an annual fair called Maghe Purnima at Kichakbadh in 2019. While science of archaeology restricts human activities in conserved places, large fairs are held in archaeologically sensitive areas of Kichakbadh posing threats to archeological wealth there. To utter dismay, archaeological crimes are still common in many sites at Kichakbadh. Multiple field-visits, questionnaire with the stakeholders, visitors and community during the fair reveal that minimal traces of community and state level endeavors to conserve the sites do not meet the vast rescue requirements that Kichakbadh is actually in need of.
\end{abstract}

Keywords: Kichakbadh, heritage management, rescue, archaeology, community, risks

\section{Introduction}

The geo-morphological features around Kichakbadh, grand palace like ruins plus a deep-moat features around the archaeological mound indicate that an ane time past, Kichakbadh might have been a fort or at least a palace (like residence) of a powerful person of repute (king, leader of a tribe-kabila). The presence of moat around the mound also indicate that this might have been at least an important and protected spot in its past glorious times and climes. Bhediyari in Morang also has similar morphology and destination 
image. The chief irony is that among archeologically illiterate communities, (my sincere apology for this terminology- which obviously is impolite but obligatory hereby to mention) the sites' considerably colossal areas conceding to the artifacts and monuments which lie buried here and there haphazardly almost everywhere reflect poor heritage management at both local and state level which has been elaborately discussed in my first phase research article published in Pragya by Nepal Pragya Pratishthan about these two places, which are of course sites themselves. ( Thapa, B.S 2076, p-182- 193) . Locals who live in Bhediyari in Morang district have found ruins of more than 200 wells and abundant other ruins of brick structures let alone precious and semi-precious stones that are treasure troves for the people here. These two sites of eastern Nepal alone can represent archaeological conditions of eastern terai region because of the ruins and monuments found here during excavations, their mythical dimensions and their religious importance within the communities living nearby. However, this article shall only report on the heritage management loopholes and communites' roles in only Kichakbadh.

\section{Kichakbadh: community and archaeology}

Communities around Kichakbadh mainly comprising of Rajbanshis, Satars and Tamangs imbue certain degree of mythical beliefs in their conducts turning it into more of religious and mythological place rather than archaeologically important site. But archaeology and myths do not go hand in hand. The labyrinth of mythical interpretations by communities around historic sites can sound absurd and bogus to an archaeologist. Similarly, the tedious and tortoise-pace of archaeological ventures are meaningless to local people who only know that the sites have been there since the times mentioned in their myths. But for a researcher like me, sensitive to both anthropological and archaeological aspects, interestingly, the invaluable riches of language, rituals, historical characters, universal norms and moral values are best preserved in local legends, myths and folklores representing both the dead and the living. Interpretation of excavated findings tells few things in place like Kichakbadh. State led excavation at Kichakbadh has comparatively dated it to Shunga- Kushan periodrelating it not older than $2^{\text {nd }}$ century B.C. Further excavations are due and apart from some local mythical interpretations, handful of occasional short mythical descriptions, touristic information in booklets nothing of much importance have been written Kichakbadh through archaeological or heritage management lens.

Lies are everywhere that can blur the real history and uplift "fake" retellings. More than that looting of artifacts is a major concern. Sharer and Ashmore rightly ascribe to looting as a long time companion of archaeology $(1987$, p. 52). They further explain the motive of looting:

The principal motive for these destructive activities remained financial or personal gain, but other forces were also responsible for an increased looting. In 
particular, a European and American colonial powers expanded into previously unexplored areas of Asia, Africa, and latin America, proprietary claims were staked over ruins in these areas, and archaeological sites were often mined like mineral deposits, to stock the shelves of museums and private collectors alike. For instance, from 1801 to 1821, Claudious Rich, a Bitish consular agent in Baghdad, collected and removed thousands of antiquities and sent them home to England. An extraordinary Italian, Giovanni Belzoni, working for the English government, systematically looted Egyptian tombs; he even used battering rams to enter the ancient burial chambers. (1987, p. 52).

This description from Sharer and Wendy just exemplifies one of many such historical acts of vandalizing to help understand contexts of looting prevailing in other forms around the globe. Among many factors that spoil the archaeological records and understanding, human activities have been ascribed to the most dangerous one. Wenke writes "The greatest destruction, however is caused by people - and not justin our own industrial age[...] still, our own generation is the perhaps the worst despoiler of antiquities" (1990. p 41-42)

Looting was a big problem in Kichakbadh too. Towards the south-east mound of Kichakbadh mound, a small island like topography called Aadradigi is surrounded on all sides by artificial narrow water bodies. Today it has been owned privately by Nim Bahadur Thapa and a small tea garden planted in around 2 bighas of land. In the past, peasants working in the field found dead bodies, many of them which had stone ornaments valued in the area. Ater B.S. 2046 in the fall of the Panchayat system,the local diggers increased, and the whole area was exploited. It would quite be relevant to state hereby the same famous adage in Archaeology- "There is no right way of digging, but there are many wrong ways" (Wheeler, 1966, p.15). The priest of Kichakbadh Satidevi temple and the locals said that most of these necklaces and stone ornaments have been sold in borderlands of India. Similar types of stone ornaments (semi- precious in nature) had been shown to this researcher in Morang's Bhediyari by one local Kamal Kishor Yadav who claimed them to have been owned by Draupadi the wife of the Pandavas mentioned in the epic Mahabharata. However, modern archaeology disapproves all forms of imaginative mythical interpretations that twist and turn the already established norms of facts and findings. All the findings are in dire need of correct dating. The voluminous epic Mahabharata is also considered as non-historical account- a big myth by many. Therefore archaeological places named with characters from this epic raise serious questionable issues for sensitive researchers like us. Treasure hunting is only one of many acts that can prove that Community's nature of ownership and behaviors invite both conservation practices and risks in archaeological sites like Kichakbadh. Both aspects of heritage management are important to convene risk mapping around the sites and develop the locations around Kichakbadh into well managed touristic destination. A local committe under the presidentship of Dil Bahadur Thebe seems to be keen on developing 
Kichakbadh into a local touristic destination with facilities and ambiences of childrens' park , however the committee also seems to be less sensitive and ignorant about archeological norms and ethics.

The whole region of Kichakbadh is a religious site in Jhapa district. According to the Mahabharata, Kichak was brother-in-law of king Virata, his queen Sudeshna's own brother. Kichak had misbehaved with the queen of the Pandavas and had strayed his lustful eyes over her. Bhima, then ruthlessly killed the Kichaka. The place where he was killed is related to be Kichakbadh in Jhapa.

Kichakbadh lies in Prithvinagar metropolis formerly called Maheshpur now in Bhadrapur village municipality by the south -western banks of the Deunia river. It is spread over 10 bigaha of lands, which is itself a mound. This mound has ruins of fences, housestructures resembling palace, and monuments linked to intangible value so it is regarded as an archaeological site. On the mound, there is one spot where a modern idol of Bhima sitting on the chest of another idol, who is undoubtedly Kichak is the prime site of the whole mound. (Fig.1). Since 2002, under the leadership of archaeologist Uddav Acharya series of excavations have been conducted in the mound.

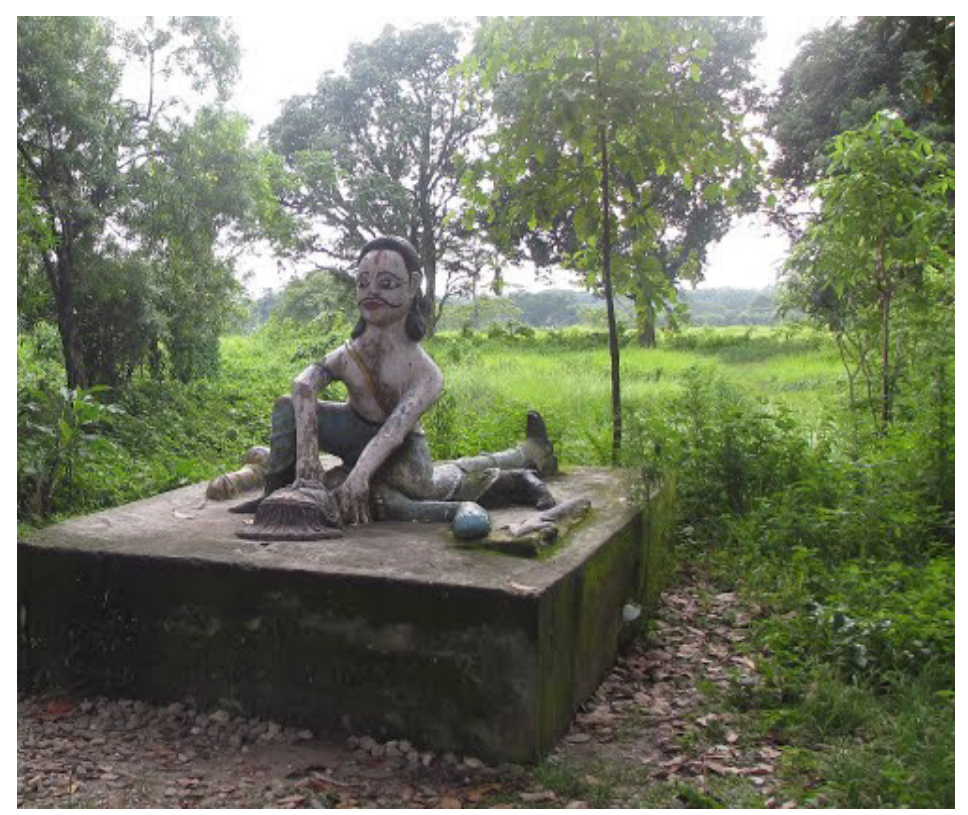

Fig.1. Local people revere their heroic character Bhimsena, offer flowers and bow here for his might and victory over Kichak. The modern image gives a quaint impression of interference in this archaeological site. (pic taken in 2018) 
Pandey and Regmi here have written about the eastern region in Nepal as areas of activities of the pre historic men. It would again be relevant to reiterate how they give an example of a finding of an axe like weapon found by one Chandra Jung Thapa in the village of Vaijanathpur of Jhapa (B.S 2062, p.65) that was retrieved from under $9 \mathrm{ft}$. Certain examples in the book claim Jhapa district and Eastern Nepal to have been pre- historic sites. The flatlands of the eastern Terai and regions around the Chure specifically in the Terai regions are inhabited by people who relate themselves to numerous events of the epic Mahabharata and Ramayana. Periods of indigenous settlements have been debated here. Dealing with regions East of Kathmandu at one point Harka Gurung writes: "In 1961, Jhapa district with a total population of 119,700 represented speakers of more than 27 languages and dialects derived from Indo-Aryan, Tibet Burman and Munda families"(B.S. 1980, p. 359). Thus the immense variety of languages indicates that Jhapa has been a much soughtafter place for refugees in search of land from diverse sources.

Excavations in Kichakbadh- in south Jhapa so far conducted do not date this site earlier than $2^{\text {nd }}$ century B.C. According to the unpublished report of Uddhav Acharya, provided to this researcher through Department of Archaeology, Nepal- about 10 bigah of the site was surveyed before dividing it into grids. After points were determined for grid, trench layouts started since 2059/10/02. The grids were divided from A to Z (except 1 and 0 ), that were done only later on (p. 1). Along with red pottery shreds, findings such as bricks of $42 \times 30 \times 5 \mathrm{~cm}^{3} 39 \times 28 \times 7 \mathrm{~cm}^{3}$ and $2828 \times 14 \times 5 \mathrm{~cm}^{3}$ have been documented in the report. (p. 2 - 3). In his another report (B.S. 2061), his second of excavation series, findings of pottery, corded wares, and roof-tiles (P. 3) and most importantly of stratigraphy (p. 4) of the site have been reported. The report states that within $180 \mathrm{~cm}$ of the trench $\mathrm{KB} \mathrm{A}^{2} 8 / 4$ seven layers were revealed. (p. 46)

Local people around here tell that when Kichaka was about to die, he asked Bhima for water. To quench the thirst of his counterpart, the mighty but soft-hearted Bhima dug a triangular pond with his elbow. This pond is tied up with another myth. This myth tells that Kichak had built a palace here so he himself built this pond. Kichak was a devotee of god Varun so this is still called Varunpokhari (Dahal, B.S. 2066 P.8). Now this pond, having religious importance for people as far as India and Bhutan has been protected by a cemented fencing through a generous businessman's funding. Keshav Dhungana, Priest of the Sati and Mahadeva temple of Kichakhadh told this researcher that Koch, who are the oldest inhabitants call Kichak as 'Kichak Thakur' and Bhima as 'Bhima Thakur'. Kichak is also sometimes related to be one of these Kochs; In the context of writing on Koch and Rajbanshis, Bista has also stated that locals in this area believed Kichak was the king of the Kochs; Kochs had participated in the war of the Kurukshetra. They firmly believed that Bhimsena had killed Kichak here. (2004, p. 160). Exploring the historicity of the Kochs, Bista has further mentioned that Kochs gradually left their religion and tradition and converted themselves to Hindus and Muslims; later on Brahman Kochs started calling Muslims Rajbanshis as Kshetriyas (p. 160). Nepal writes that before the advent of the Royal Shahs, along with Rai, Limbu, Koch and Sens, had ruled Vijaypur, but their reign had been 
terrifying for people (B.S. 2040, p. 279). Sharma writes that there were 6 types of forts in tradition during the Mahabharata. They were mahi, giri, manusya, jal and vana durgas (fort) (B.S. 2055, p. 7). Kichakbadh site shows combination of three forts-mahi,jala and vana.

In the excavation sessions the ruins of bastions were found in the south-west and in the North side of the Kichakbadh mound. These too indicate that this might have been a place of importance of a powerful personality of the past-period, whose history we lack. The probability of village settlements of common people around this place of repute cannot be denied. Some locals have narrated their own tales- recounting on their hear-says that this site might have been a 'naachghar' (theatre- house) of the king Virata or palace of the Kichak himself.

An annual festival called Maghe purnima is held in the site. Preparations are heavy and hasty that begin months prior to the festival. Traders from nearby hilly areas and India assemble and start preparing for temporary make shift settlements in and around the sites. As there are no hotels and inns, the small mound of Kichakbadh seems dangerously tiny and vulnerable amidst mass of more than 2-3 lakhs of people who assemble during the one day festival. Thousands and thousands of people attend the yearly festive in the month of Falgun. (on Full-moon day). This has changed the destination image of Jhapa and called on urgent measures to protect it from effects of human activities, management loopholes (Fig2) and safeguard this cultural property from natural disaster like river-floods too.

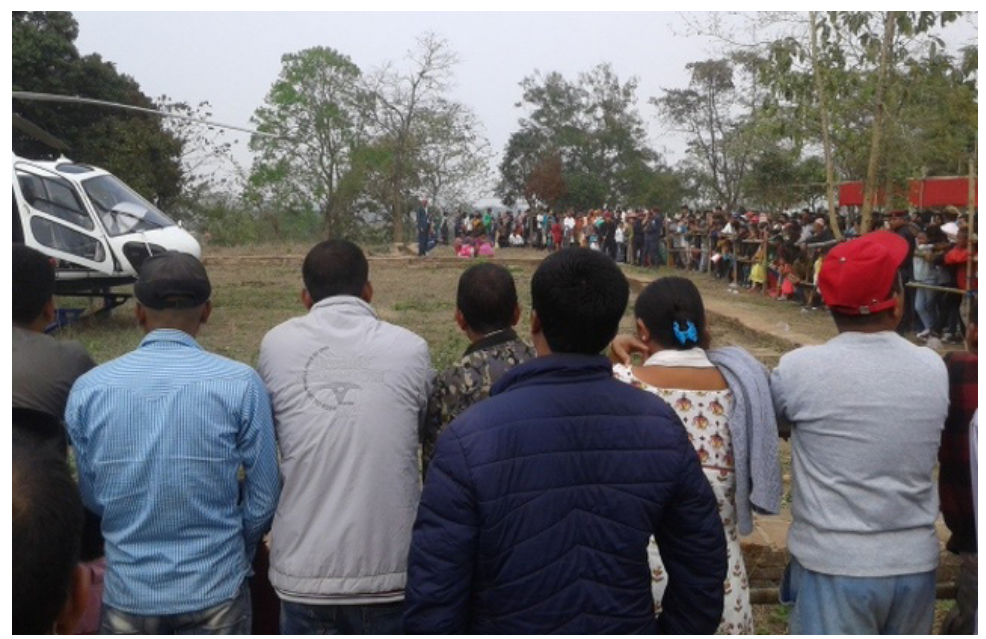

Fig. 2 . Helicopter landing in sensitive conserved area inside of an archaeologically protected site in Kichakbadh among excited visitors -2019, Feb. 17.

During 2018 annual festival short helicopter ride were organised by Kichakbadh Conservation Committee from the archaeological mound to a place call Baniyani. This had raised much havoc in the fair, polluting it with dust among running and shrieking 
congregation stirring people hither and tither on the conserved areas, walls and ruins in the mound. Sites around Kichakbadh have also been dug numerous times by local people in search of treasure, precious and semi-precious stones and ancient objects of antique values.

Mismanagement of heritage sites have time to time been discussed globally. Mcglade's article on Hardrian World Heritage Site, UK depict how after opening of Hadrian's wall path national trail (a $135 \mathrm{~km}$ recreational walking route ) did damage to the archaeological fabrics of the wall (2018,p.189). Several man made walking routes have been left as it is over archaeological ruins in Kichakbadh mound. Tresspassing, cattle grazing and littering are common and not recognized as faults in the area, let alone picnicking and merry making during the winter season.

\section{Discussion}

During annual fair of 2018 at Kichakbadh, questionnaires were given both to visitors and community. Only one aspect of the questionnaire relatin to risk factors will be interpreted in this short article hereby.One of the questions during the questionnaire filling was "What risks did you see here in the Kichakbadh site? 84 out of 160 random samples from the visitors attending the Kichakbadh annual festival responded that people's movement and activities were the risks for the sites. 36 of them pointed to the fact that river flowing by is the main risk; 18 felt lack of ownership by community; 6 referred to local level indifference and 16 of the respondents had no idea about the risks. Interestingly, among 10 samples from the Kichakbadh community who visited the temple premises everyday or at much once a week, only 1 respondent felt that people's random movements and activities are the risks in the site. 3 of them pointed to community's lack of ownership, 3 pointed to state and local level's indifference and 3 pointed to the river. The data is further simplified in the pie charts below:

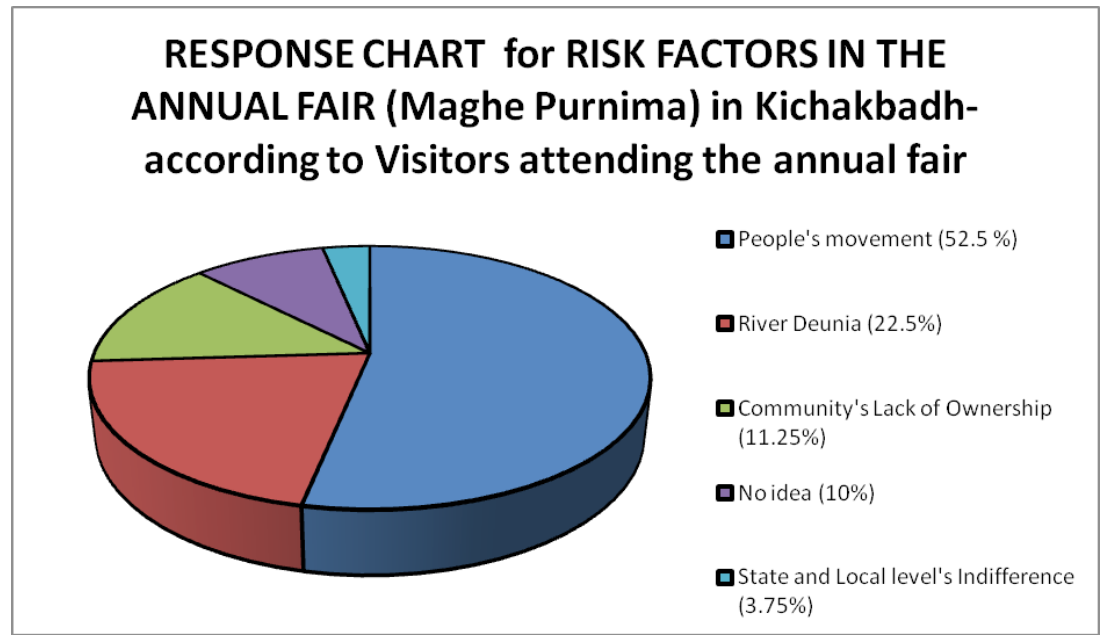

Pie Chart- 1 


\section{RESPONSE CHART for RISK FACTORS - according to the community people living by the Kichakbadh mound premises}

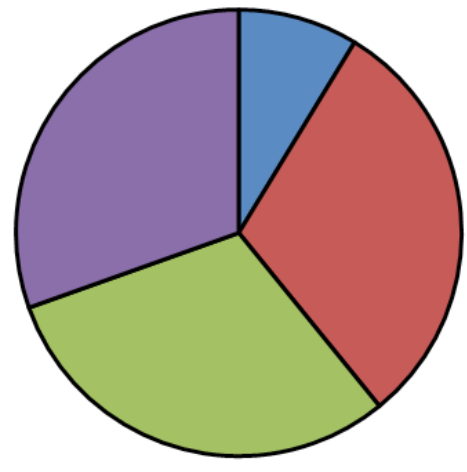

口People's Movement (10\%)

口River Deunia (30\%)

口Community's lack of Ownership (30\%)

口State and Local Level's Indiffernce (30\%)

Pie Chart -2

It is obvious that the community sample number is far to less for the time being to be interpreted, but findings obviously point to the bitter fact that community does not feel that people's movements in the fair pose threats to archaeological monuments here. The most convincing interpretation of the fact can be that visitors- most of them have no idea how the mass moves on in the Kichakbadh mound on other days apart from the annual fair they attend. Community persons know this and it is obvious that on other days hardly 50 people on average commute through the mound- posing almost no challenge to the monuments in the eyes of the community people. More findings and data collection are being carried out by this researcher to aid on heritage management issues in and around the site.

The role of community in religious fairs like these is obviously important but their understanding of threats for the site needs further illumination, exposure and trainings. Today's era in heritage management is always inside the impact zone of international conventions to most of which, Nepal is also a party-state. 2003 Convention for the safeguarding of the Intangible Cultural Heritage mentions about value of community as- "each state party's shall endeavor to ensure the widest possible participation of the communities, groups and where appropriate individuals that create, maintain and transmit such heritage, and to involve them actively in its management"(Article 15). Risk- mapping, intertwining community's role to public archaeology, topographical mapping in and around sites, assessing touristic/ visitors' ambiences are some heritage management issues to be addressed in both sites Kichakbadh and Bhediyari. Both at local and state level the eastern parts of Nepal have been underprivileged. Small scale endeavors are on the way but not sufficient. Numerous ponds, sites, mounds, pilgrimages, sites of local-performances carry interesting and popular myths of the Mahabharata age to that of the Pauranic period. Taking Kichakbadh as a vantage piont to other 4 directions until Bhediyari in the west and even beyond the Koshi river, a 
fast-developing civilization could have existed for long time. Some forms of war, epidemic, natural disaster etc. could have been the reason of the collapse of this historical region. When nomadic indigenous groups like Koch, Dhimal came here, they should have brought some hear-says and myths of this place.

A Satar man singing a song to the idols of Bhima and Kichaka during Maghe Purnima in Kichakbadh and a Rajbanshi relating Bhediyari to Pandavas' incognito years can be more sensitive and important anthropologically than archaeologically. Similarly, the fortifications, monuments and brick layouts in the sites reflect more history of the site through archaeological lens. Heretofore, the inter-related facets of myths and archaeology or anthropology and archaeology in construction of history, at least a regional history should be respected as legacy for future-researches but their risks that could distort history should be studied unbiased. While discussing on "The Intergrative Imperatives of Human Culture", Malinowsky writes " any discussion of symbolism without its sociological context is futile, like any assumption that culture could originate without the simultaneous appearance of artifacts, techniques, organization, and symbolism (1961, p. 136). The importance of individual habits and achievements for the benefit of community and tradition has been well dealt in the text. Therefore, it is high time that archeologists, researchers and stakeholders focused their interdisciplinary conscience to take vigilant notices on indigenous people how they see the archaeological monuments- to relate here people like Satar who sing songs on the site of Kichakbadh to help heritage workers devise proper heritage plan in the area.

The main temple of Sati Devi in the Kichakbadh mound is being shifted towards the northern lowland of the mopund to clear original space of the temple for further archaeological ventures and study of low er layers of the soil. Shifting of temple, undoubtedly will not please the community people and religious and staunch devotees. New researchers in the future and professional archaeologists should also explore places that have oral stories ( oral narratives) in the region to acquaint themselves with the local importance of the site because exploration and excavation is not just surveying and digging, it is also building rapport with the community, promoting ownership and transmitting responsibility for promoting citizenarchaeology. Integrating communities and stakeholders to responsibilities of archaeological places like Kichakbadh is a series of processes which when accomplished will rule out epistemological violence in and around the sites- for examples helicopter ride in the annual fair, treasure hunting, picnicking (merry-making) vandalizing or even remaining indifferent to disasters and risks.

\section{Acknowledgement}

This researcher bestows his sincere acknowledgements to Professor Peshal Dahal for his careful guidance and advice during the research venture. Students of class 8 and 9 of Shree Rudra Memorial Higher Secondary School, Birtamode and their Social Studies teacher Mr. Tapan Khadka all deserve abundance of thanks for their helpful volunteering and assistance during the questionnaire session in the annual festival Maghe Purnima of Kichakbadh. 


\section{References}

Acharya,U. Kichakbadh excavation project, preliminary report- B.S. 2058/2059. Ministry of Culture, Tourism and civil Aviation, Department of Archaeology, Nepal. (Unpublished report)

Kichakbhadh excavation project, excavation reports- B.S. 2060/2061.Ministry of Culture, Tourism and Civil Aviation, Department of Archaeology, Nepal. (Unpublished report).

Bista, D.B. (2004). People of Nepal. Kathmandu: Ratna Pustak Bhandar.

Dahal, C. "Kichakbadh dharmik, aitihasik tatha paryatakiya sthal" (Religious, historical and touristic aspects of Kichakbadh). Kichakbadh Smarika (Kichakbadh souvenir). (B.S. 2066). In Chintamani Dahal, Giri Gopal and others (Eds.). Prithvinagar: Kichakbadh Sangrachyan samitee.

Gurung, H. (1980). Vignettes of Nepal. Kathmandu: Sajha Prakashan.

Maliwonsky, B. (1960). A scientific theory of culture. New York: Oxford University Press.

Mcglade, D. (2018). "Visitor Management in sensitive historic landscapes: strategies to avoid conflict in Hardrian's wall world heritage site". In Laurent Bourdeav \& et. al (Eds.) World heritage sites and tourism: global and local relations. India:Routledge.

Nepal, G. Nepal Nirukta. (B.S. 2040, 1st Edition). Kathmandu: Nepal Rajkiya Pragyan Pratisthaan.

Pandey, R.N. \& Regmi, D.C. (B.S 2062). Nepalko prag itihasas (Pre- History of Nepal). Kirtipur: CNAS.

Sharma, D. R. (B.S.2055). Nepalko killa vastukala (Fort architecture of Nepal). Kirtipur: CNAS.

Sharer R. J \& Ashmore W. (1993, 2nd edition). Archaeology: discovering our past. California: Mayfield Publishing Company.

Thapa, A. (B.S. 2076). "Purbi Nepalko aitihasik sthalharusanga jodiyeka mithhak ra puratatwik gatibidhiharu" (Myths and archaeological ventures around historical sites in eastern Nepal). Pragya. Kathmandu: 117, 182-192.

Wenke, R. J . (1990). Patterns in Prehistory. New York: Oxford.

Wheeler, M. (1966). Archaeology from the earth. London: Penguin Books.

Convention on Safeguarding of Intangible Cultural Heritage, (2003), UNESCO. 